\title{
Use of an additional working channel for endoscopic mucosal resection (EMR+) of a pedunculated sessile serrated adenoma in the sigmoid colon
}

A 64-year-old man was admitted to our hospital after screening colonoscopy revealed multiple polyps including a tumor-suspicious lesion in the transverse colon. Ileocolonoscopy revealed a flat adenoma at the cecum and a colorectal tumor of the transverse colon in close proximity to the right colonic flexure. As an extended right hemicolectomy was considered the treatment of choice, neither lesion was removed during colonoscopy. In the rectosigmoid, however, an additional large pedunculated polyp (Paris 0 -Ip, $2 \times 1 \times 5 \mathrm{~cm}$ ) with a broad base was detected. Owing to the flat base, an unfavorable location behind a colonic fold, and high mobility of the polyp, a conventional endoscopic mucosal resection (EMR) procedure was difficult to perform. Consequently, we decided to perform a novel grasp-and-snare technique termed EMR + technique ( $\triangleright$ Video 1$)$.

After submucosal injection of hydroxyethyl starch 6\% (B. Braun, Melsungen, Germany), the polyp was successfully resected (Endocut Q 1/1/1) in toto with a 20 mm snare (Captivator II; Boston Scientific, Marlborough, Massachusetts, USA) after pulling the polyp with a standard grasper via an additional working channel (AWC) ( Fig.1) through the snare ( $\triangleright$ Fig.2). Histopathology revealed low grade dysplasia in a sessile serrated adenoma and $\mathrm{R} 0$ resection.

Classical EMR is an established endoscopic procedure for resection of colonic polyps [1]. Nevertheless, large or laterally spreading lesions $\geq 2 \mathrm{~cm}$ can be challenging and, in fact, EMR often results in a piecemeal resection with unclear completeness of the resection base [2]. Recently, a commercially available system called EMR + was launched [3], where EMR is conducted with an AWC (Ovesco Endoscopy AG, Tübingen, Germany). The AWC is mounted at the tip of a standard gastroscope or pediatric colonoscope [3], resulting in a double-channel endoscope system that potentially improves

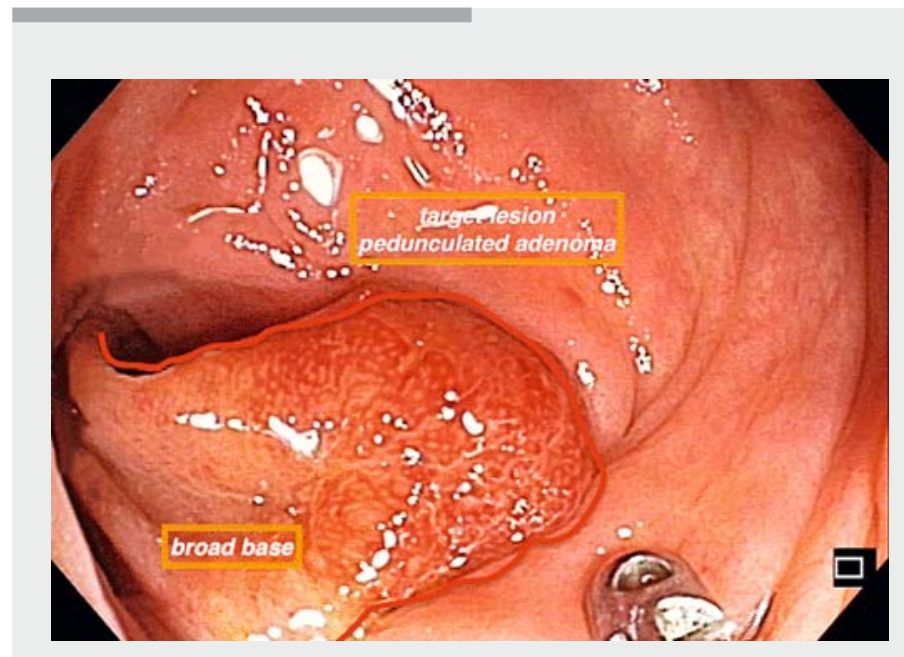

Video 1 The endoscopic mucosal resection (EMR) with additional working channel $(E M R+)$ procedure for removal of a pedunculated serrated adenoma in the sigmoid colon. Source for graphical details in the video: Ovesco Endoscopy AG, Tübingen
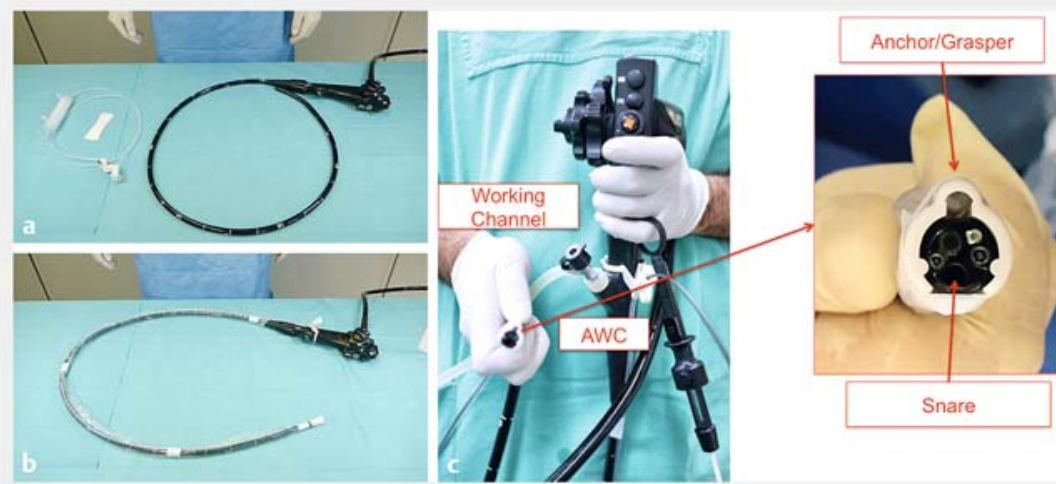

- Fig. 1 The novel endoscope system. a The additional working channel (AWC) before installation. b The scope after installation of the AWC. c The working instruments through the AWC and the working channel. In addition, the position of the AWC can be changed at the distal end of the endoscope in order to vary the angle of the instruments.

the resection rate of challenging lesions by using the grasp-and-snare technique [4-5]. By turning the cap, variable positions of both working channels (AWC plus standard channel) can be achieved. The EMR+technique using the AWC could be a practical and inexpensive method of overcoming the limitations of classical EMR and may enable intraluminal bimanual working for resections larger than $\geq 2 \mathrm{~cm}$.

Endoscopy_UCTN_Code_TTT_1AQ_2AD 


\section{$\mathrm{EMR}+$ procedural steps}

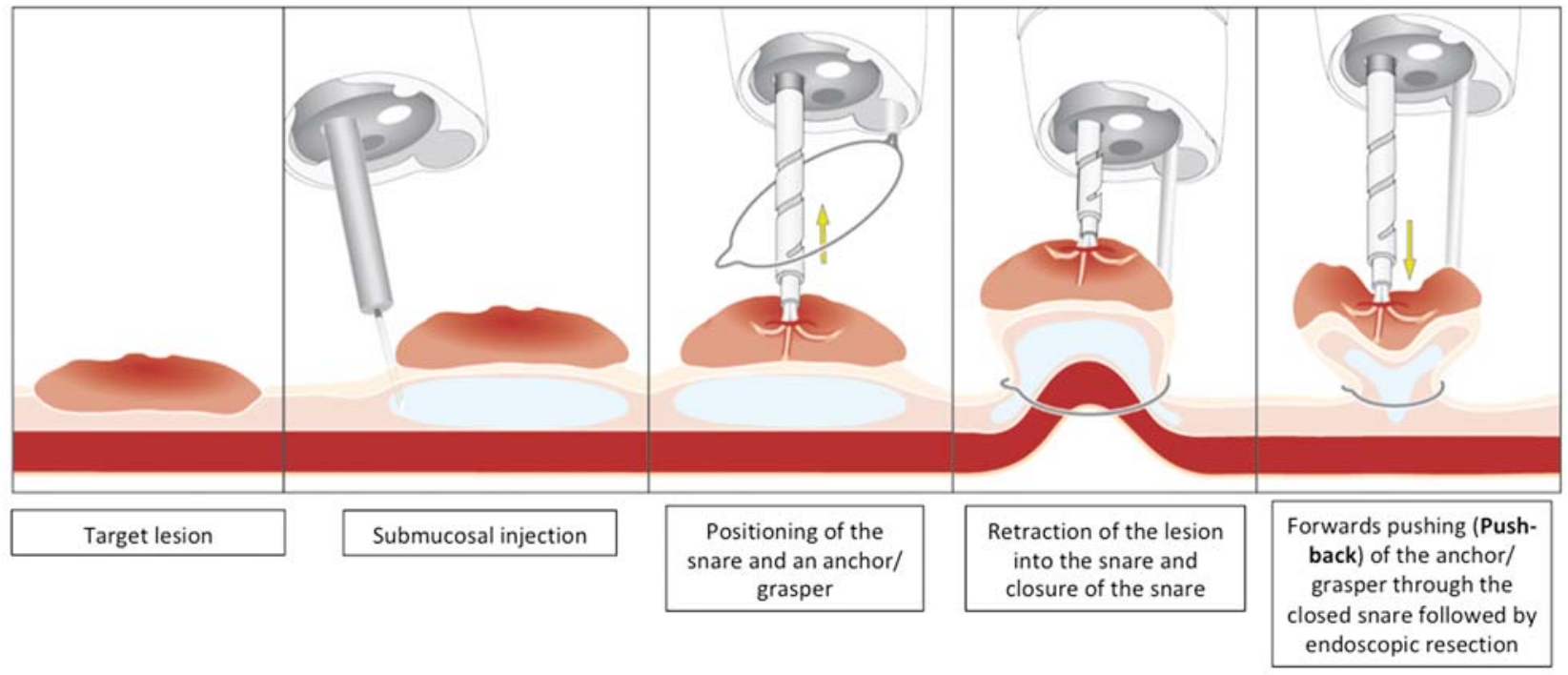

- Fig. 2 Procedural steps of endoscopic mucosal resection (EMR) with the additional working channel (EMR+). Source: Ovesco Endoscopy AG, Tübingen

\section{Competing interests}

None

The authors

Edris Wedi, Richard F. Knoop, Carlo Jung, Volker Ellenrieder, Steffen Kunsch Department of Gastroenterology and Gastrointestinal Oncology, Center of Interdisciplinary Endoscopy University Medical Centre Göttingen, Göttingen, Germany

\section{Corresponding author}

\section{Edris Wedi, MD}

Interdisciplinary Endoscopy, Department of Gastroenterology and GI Oncology, University Medical Center Göttingen, GeorgAugust-University, D-37075 Göttingen, Germany

edris.wedi@med.uni-goettingen.de

\section{References}

[1] Ferlitsch M, Moss A, Hassan C et al. Colorectal polypectomy and endoscopic mucosal resection (EMR): European Society of Gastrointestinal Endoscopy (ESGE) Clinical Guideline. Endoscopy 2017; 49: 270 - 297

[2] Wang J, Zhang XH, Ge J et al. Endoscopic submucosal dissection vs endoscopic mucosal resection for colorectal tumors: a meta-analysis. World J Gastroenterol 2014; 20: $8282-8287$

[3] Walter B, Schmidtbaur S, Hann A et al. Improved endoscopic resection of large flat lesions using an external additional working channel (AWC). Endoscopy 2018; 50: S99

[4] Shetty A, Suarez AL, Dufault DL et al. Endoscopic mucosal resection with grasp-andsnare technique for challenging lesions. Gastrointest Endosc 2016; 84: 738 - 739

[5] von Renteln D, Schmidt A, Vassiliou MC et al. Endoscopic mucosal resection using a grasp-and-snare technique. Endoscopy 2010; 42: 475-480

\section{Bibliography}

DOI https://doi.org/10.1055/a-0809-4814

Published online: 11.1.2019

Endoscopy 2019; 51: 279-280

(c) Georg Thieme Verlag KG

Stuttgart · New York

ISSN 0013-726X

\section{ENDOSCOPY E-VIDEOS}

https://eref.thieme.de/e-videos

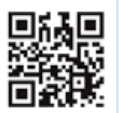

Endoscopy E-Videos is a free access online section, reporting on interesting cases and new

techniques in gastroenterological endoscopy. All papers include a high quality video and all contributions are freely accessible online.

This section has its own submission website at https://mc.manuscriptcentral.com/e-videos 